\title{
Música e disco no Brasil: A Trajetória de André Midani
}




\section{Resumo}

Esse artigo tem por objetivo apresentar a trajetória profissional de André Midani, provavelmente o mais importante executivo da história da indústria fonográfica no Brasil. Nascido na Síria, Midani chegou ao Brasil nos anos 50, ingressando imediatamente na indústria. Sua trajetória, desenvolvida especialmente nas gravadoras Odeon (EMI), Phillips/Polygram (Universal Music) e Warner, está profundamente ligadas a importantes movimentos da música popular brasileira como a Bossa Nova, o Tropicalismo, a Brazilian Black Music e o Rock Brasileiros dos anos 80 . Além disso, o modelo de atuação empregado por Midani - baseado, segundo suas palavras, na promoção do artista e não da música - pode oferecer um interessante contraponto para a discussão do cenário atual e da crise que parece atingir globalmente a indústria do disco.

\section{Palavras-chave}

André Midani, música, músicos.

\section{Abstract}

This paper presents the professional trajectory of André Midani, a man who probably is the most important manager in the history of Brazil's phonographic industry. Midani was born in Syria and during the 1950 decade came to Brazil, where he immediately started on the music industry. His story is deeply connected to important Brazilian Popular Music movements such as Bossa Nova, Tropicalismo, Brazilian Black Music and the 1980's Brazilian Rock, styles whose was mainly developed inside the record labels Odeon (EMI), Philips/ Polygram (Universal Music) and Warner. In parallel, the observation of the administrative model Midani has employed, according to his own words based on the promotion of the musician and not the music, can offer an interesting contrast for discussing the today's scenario and the crises of phonographic industry worldwide.

\section{Keywords}

André Midani, music, musicians. 


\section{Introdução}

quipamentos de gravação e reprodução de áudio são
comercializados desde a década de 1880 e a audição de música
gravada é, certamente, responsável pela formação da memória musical da quase totalidade dos indivíduos nascidos nos últimos 80 ou 90 anos. Essa presença hegemônica da música industrializada talvez nos leve a esquecer que, ao falar sobre a música popular de um certo período ou sobre o que muitos consideram como a pobreza estética e intelectual da música atual, não estamos falando sobre toda a produção musical existente, mas sobre aquela que empresas ou indivíduos decidiram, em algum momento, registrar em algum formato, distribuir e divulgar por diferentes meios.

Assim, quando refletimos sobre a riqueza e sofisticação da música desenvolvida no Brasil, notadamente ao longo das décadas de 60 e 70, por exemplo, talvez valha a pena atentar para a importância dos executivos e produtores envolvidos nessa atividade, num momento em que o satisfatório retorno financeiro, aliado à precariedade dos meios de produção e dos conhecimentos mercadológicos, talvez possibilitasse uma atuação mais marcante desses profissionais, capaz de imprimir sua marca pessoal às empresas que comandavam.

Dentre essas figuras, André Midani é, sem dúvida, um dos nomes de maior destaque, e não me parece possível discutir a história da indústria fonográfica brasileira sem considerar o papel que ele desempenhou a frente de empresas como Odeon (hoje EMI), Phillips/ PolyGram (hoje Universal) e WEA (Warner). 
Construí a narrativa que se segue a partir de entrevistas e matérias jornalísticas publicadas ao longo da carreira de Midani, de um artigo de sua autoria publicado recentemente, de uma entrevista em áudio disponibilizada na Internet e de um depoimento pessoal, que me foi generosamente concedida em fevereiro de 2007. O presente texto é parte de uma pesquisa mais ampla sobre a memória oral da indústria fonográfica brasileira que estou realizando, enquanto professor do CTR/ECA/USP, ' com o apoio financeiro da FAPESP (Fundação de Amparo à Pesquisa do Estado de São Paulo).

\section{O início da carreira}

Haidar Midani nasceu na Síria, em 1932. Seu pai era membro de uma família tradicional daquele país e, sua mãe, uma francesa de origem judia. Ambos haviam se conhecido na França, durante a universidade, e decidiram - para evitar qualquer discussão sobre opção religiosa entre as duas famílias - batizar o filho no catolicismo. Sua permanência na Síria foi curta: seus pais se separaram quando tinha onze meses de idade e ele foi levado para a França pela sua mãe, onde viveu em Paris e na Normandia ${ }^{2}$

Mais tarde, ele assumiu o nome "Andre" como forma de ocultar sua origem Síria.

Seu interesse pela música começou aos 12 anos de idade, com o jazz dixieland. Ele também ficou fortemente impressionado, por essa mesma época, ao ver pela primeira vez um gramofone. Conforme suas lembranças, o impacto desse primeiro contato foi tão forte que ele chegou a dizer, naquele momento, que um dia iria trabalhar naquela atividade, produzindo discos ${ }^{3}$. Midani começou a tocar bateria pouco tempo depois e, entre os 17 e os 19 anos, chegou

1. Departamento de Cinema, Rádio e TV da Escola de Comunicações e Artes da Universidade de São Paulo.

2. A familia residia na Normandia durante o Dia $\mathrm{D}$ e teve sua casa destruída durante os combates de 06 de junho.

3. Conforme depoimento concedido ao autor em fev/2007. 
a se apresentar em casas noturnas com certa freqüência e, em pelo menos uma ocasião, acompanhou Sidney Bechet, substituindo o baterista oficial da banda ${ }^{4}$.

Mas André não tem lembranças tão felizes do período:

Eu era um péssimo músico... Aí, achei que a coisa mais próxima de ser músico era trabalhar em disco... Primeiro fui à Odeon de lá, porque a Pathé Marconi não tinha emprego. Fui à Ducretet Thompson, não tinha emprego. Aí, entrei na Decca, no estoque, para arrumar discos. Em um ano e meio eu estava na gravação. ${ }^{5}$

Apesar da afirmação acima, Midani parece não ter estado diretamente envolvido com o processo de gravação durante sua presença na Decca francesa, iniciada em 1951. Suas intervenções na produção, segundo o depoimento que me foi prestado, teriam se dado através das sugestões para a gravação de dois trabalhos (ou, como ele prefere descrever, através de "dois acidentes"). O primeiro e mais significativo, foi o do registro, por Fernandel, em 1954, de Les Lettres de Mon Moulin, de Alphonse Daudet. Midani ouviu pela primeira vez a interpretação do ator para La Chevre de M. Seguin (um dos textos da coletânea de Daudet) durante um sarau promovido por uma atriz da Comedie Française. Midani lembra-se de ter ficado encantado com a força do texto declamado, especialmente por tê-lo considerado enfadonho quando o lera na escola fundamental. Ele atribui o sucesso da gravação - ainda hoje disponível em CD principalmente a essa presença do texto no currículo escolar, que seria a grande justificativa comercial para a sua produção. As gravações foram dirigidas por Claude Colombini.

Pouco depois ocorre o segundo "acidente", quando Midani recebe a informação, fornecida por um membro de uma sociedade

4. O baterista era François "Moustache" Galipedes e sua banda era a Claude Luter et Son Orchestre, provavelmente o mais tradicional grupo de dixieland da França.

5. Midanimidanimidani, O Pasquim - um ponto de vista carioca, 25/02/1974. 
de estudos da história militar francesa denominada La Sabretache, de que haviam sido encontradas partituras originais de marchas militares do exército de Napoleão. Novamente por sua sugestão, essas peças são gravadas pela Decca em EPs $(45 \mathrm{rpm})$, recebendo o nome de As Marchas Imperiais de Napoleão.

De qualquer maneira, esses dois "acidentes" ajudam a evidenciar não apenas o interesse de Midani pela área de produção e sua capacidade de intuir nichos de mercado, como a própria disponibilidade da indústria - ao menos naquele momento - para a exploração dessas novas possibilidades.

Midani demite-se da Decca em 1954 e acaba se engajando, como produtor e vendedor de discos, numa expedição promovida pelo Ministério da Cultura Francês com a finalidade de registrar manifestações folclóricas musicais na África. Ele deveria vender discos de música francesa e, ao mesmo tempo, cuidar do registro da música local em um dos caminhões da expedição (que dispunha de um estúdio móvel). Planejada para durar sete meses, a viagem acabou interrompida por conta da instabilidade política em Camarões, ${ }^{6}$ onde todos os caminhões foram incendiados. Assim, Midani volta prematuramente à França com uma significativa indenização pela interrupção da viagem.

Era o início da Guerra da Argélia (1954-1962), e vários amigos e parentes de Midani estavam sendo convocados para a luta. Não desejando engajar-se numa guerra em que - segundo suas palavras - não acreditava, ainda mais considerando-se sua origem Síria, ele decide deixar a França o mais rápido possível, fugindo da convocação militar. A decisão de vir para o Brasil deu-se por exclusão: era um dos poucos países onde conseguiria entrar sem visto. Sua idéia era passar apenas alguns dias no país, do qual quase nada sabia, e depois seguir para a Argentina. Porém, quando o navio adentrou a Baía da Guanabara, no final de 1954, a beleza do cenário o comoveu e ele decidiu permanecer no Rio.

6. Os incidentes em Camarōes ocorreram, muito provavelmente, em função da campanha pela independência e reunificação das áreas francesa e britânica promovida pelo Cameroon People's Union. 


\section{A chegada ao Brasil}

Midani ingressa na indústria fonográfica quase imediatamente após sua chegada ao país, e de um modo bastante curioso. Procurando emprego, ele acaba contatando por telefone o escritório da Odeon. ${ }^{7}$ Como não fala português, tenta se comunicar em seu inglês precário com a secretária, que acredita tratar-se de um enviado europeu da gravadora em visita ao país. Por conta disso, é recebido pelo presidente da gravadora já no dia seguinte! De qualquer forma, após o mal-entendido ser esclarecido, Midani acaba contratado como gerente de produto do selo Capitol, recém adquirido pela Odeon. Para André, essa foi uma sorte formidável pois o Brasil, na sua visão, era um país muito isolado culturalmente, mesmo quando comparado a vizinhos como Argentina e Chile. Por isso, pouco se sabia aqui sobre artistas do selo como Stan Kenton, Frank Sinatra e Nat King Cole, que Midani, como grande apreciador de jazz, conhecia muito bem. Isso lhe garantiu sucesso na função e um bom início para a sua carreira no país.

Deixando de lado seu componente exótico, vale notar que a contratação de Midani se dá no momento em que, como observa Renato Ortiz (1994), o país vivia a constituição de um mercado consumidor que "sem se transformar em massa, define sociologicamente o potencial de expansão de atividades como o teatro, o cinema, a música e até mesmo a televisão... uma audiência específica, mas considerável, formada pelas camadas urbanas médias" (Ortiz: 1994, p. 102). É essa audiência que responderá pelo consumo de jazz e, logo depois, pelo de Bossa Nova. Assim, Midani chegava aqui já afinado com as vertentes que iriam demarcar, no campo da música popular, a grande efervescência brasileira dos anos seguintes. Em 1978, ao falar de sua participação no surgimento da Bossa Nova, Midani acaba por se referir a essa questão:

7. A gravadora Odeon, atualmente parte da EMI, instalou sua primeira fábrica no Brasil em 1913, numa associação com Frederico Figner, pioneiro da indústria fonográfica no país (Vicente, 2002: 309). 
A participação que eu tive na Bossa Nova - e olha que não estou querendo dizer que fui responsável por nada - foi de certa maneira importante, porque eu tinha, naquela época, o dinheiro da promoção e da publicidade. Quando eu cheguei ao Brasil, uma coisa que me desagradava muito era ainda esse símbolo de vozeirão. Era ainda época da tradição da música de voz grande. $E u$, francamente, nunca havia transado esse tipo de voz, porque na França já estávamos na época existencialista... Eu tinha o dinheiro e era uma das pouquíssimas pessoas dentro do meio que acreditava que esse estilo de música fosse vingar ou tivesse futuro. ${ }^{8}$

Aloysio de Oliveira que ocupou papel central não só nessa aproximação de Midani com a Bossa Nova, como também em toda a sua atuação posterior dentro da indústria. Aloysio ${ }^{9}$ chegou à Odeon um pouco depois de Midani, em 1956, e a indentificação entre ambos foi imediata. Como Aloysio assumiu a função de diretor artístico e Midani passou a responder pela divulgação, ambos estabeleceram uma parceria estratégica, apoiando-se mutuamente. Para Midani, sua ligação com Aloysio deveu-se também ao fato de que, considerando a origem européia de Midani e a vasta experiência de Aloysio nos EUA, "os dois eram estrangeiros dentro de uma estrutura brasileira muito obsoleta". ${ }^{10}$ Assim, enquanto Aloysio apresentava a Midani artistas de sua geração como Dorival Caymmi, Fernando Lobo e Antonio Maria, entre outros, além de nomes fundamentais da Bossa Nova como Tom Jobim e João Gilberto, Midani, por seu lado, fortalecia os projetos de Aloysio com verbas de seu departamento. Foi esse o caso, por exemplo, quando da contratação de João Gilberto e do lançamento de seu disco 78 RPM com as faixas Chega de Saudade

8. Midanimidanimidani,op. cit.

9. Aloysio fora integrante do Bando da Lua e esteve nos EUA, acompanhando Carmen Miranda, desde sua chegada, em 1939, até a morte em 1955.

10. Depoimento concedido ao autor, op. cit. 
(Tom Jobim/Vinícius de Moraes) e Bim Bom (João Gilberto), em agosto de 1958.

Posteriormente, Midani assumiria também a responsabilidade pelas capas dos discos da gravadora. Ele "achava que as capas estavam muito feias naquela época" ${ }^{11} \mathrm{e}$, para sua produção, acabou contratando profissionais como o designer César Vilela e o fotógrafo Chico Pereira, que iriam acabar mundialmente conhecidos pelos trabalhos realizados posteriormente para o selo Elenco, de Aloysio de Oliveira. Chico Pereira acabou ainda por auxiliar Midani em seu processo de socialização no Rio de Janeiro, introduzindo-o a um grupo de artistas do qual faziam parte Roberto Menescal, Nara Leão e Ronaldo Bôscoli, entre outros. Para a produção das capas dos discos Midani contrataria, ainda, Otto Stupakoff, que viria a se tornar o pioneiro na fotografia de moda no país ${ }^{12}$ Sempre segundo Midani, Stupakoff acabava de retornar ao país depois de seus estudos em Los Angeles. Tinha por volta de 23 anos e se encontrava em dificuldades financeiras por não conseguir trabalho junto às agencias de publicidade.

A Odeon, através de Midani, desenvolveu várias ações promocionais de apoio à Bossa Nova, com destaques para o show da Faculdade de Arquitetura, ${ }^{13}$ para a produção de um jornal especializado em notícias musicais e para o que Midani aponta como os primeiros anúncios publicitários de música brasileira na imprens $\mathrm{a}^{14}$.

Mas, apesar de tudo isso, a Bossa Nova não era bem recebida pela conservadora direção da Odeon, ${ }^{15}$ que preferia investir em um

11. Idem, ibidem.

12. Sempre segundo Midani, Stupakoff acabava de retornar ao pais depois de seus estudos em Los Angeles. Tinha por volta de 23 anos e se encontrava em dificuldades financeiras por não conseguir trabalho junto às agencias de publicidade.

13. O show aconteceu em 20 de maio de 1960 e se chamou "A noite do amor, do sorriso e a flor", sendo considerado o primeiro grande evento de Bossa Nova realizado no país.

14. Midanimidanimidani, op. cit.

15. Os confrontos mais sérios parecem ter sido com Henri Jessen que era, na ocasião, assistente de Bill Morris, presidente da Odeon. Dicionário Cravo Albin da Música Popular Brasileira:http://www.dicionariompb.com.br/verbete.asp? tabela=T FORM B\&nome=Andr\%E9+Midani 
artista como Ary Barroso, de maior apelo popular, do que em Tom Jobim, que possuía poucas músicas de sucesso. Em virtude desses confrontos, Aloysio deixa a Odeon em 1960, indo para a Phillips. Midani se afasta pouco tempo depois.

É interessante observar que o caráter de confronto com a tradição musical estabelecida, proposto pela Bossa Nova, acaba por envolver também os executivos das empresas. Midani estava sintonizado com um público mais jovem, ao qual a Bossa Nova se dirigia, e que não era, naquele momento, o público visado pela Odeon (ou pela indústria fonográfica brasileira como um todo). Entendo que a opção por esse público só se daria a partir da consolidação da televisão como meio de divulgação musical, especialmente através dos festivais de música da década seguinte, quando a influência da Bossa Nova iria mobilizar toda uma nova geração de criadores.

Após a saída da Odeon, Aloysio e Midani seguem trajetórias um tanto diferentes. Aloysio ingressa imediatamente na Phillips e, ao deixar essa empresa, em 1962, funda a gravadora Elenco, através da qual produz e lança, entre 1963 e 1967, mais de 60 discos "com a participação dos maiores nomes da Bossa Nova" (Zan: 1998, p. 67). A empresa, no entanto, nunca se consolidou e acabou adquirida pela própria Phillips já em 1967 (Idem, p. 68/69). Midani ficaria alguns anos afastado das grandes gravadoras e também criaria sua própria empresa, mas com preocupações bem diferentes das de Aloysio.

\section{A Imperial Discos e a Capitol Mexicana}

O projeto independente de Midani chamava-se Imperial Discos. Para o início das atividades, ele utilizou o dinheiro que recebeu pela rescisão de seu contrato com a Odeon: aproximadamente $30 \mathrm{mil}$ dólares. Com essa verba, ele conseguiu gravar por volta de 12 discos "de dança, bolero, tango valsa, aquele negócio todo..."16. Utilizando uma prática que depois se tornaria comum no país, muitas das

16. Midanimidanimidani, op. cit. 
orquestras e artistas gravaram com pseudônimos que sugeriam uma origem estrangeira ${ }^{17}$ e Midani iniciou um sistema de vendas de porta em porta nas cidades do Rio e de São Paulo:

O Chiquinho gravou um disco lá. Eu me lembro que nos primeiros arranjos - o nome dele era Chiquinho de Moraes - a orquestra saía como Frank Moraes. Tínhamos o Pattané, a orquestra saía como não sei o quê do Caribe. Não me lembro. Pra mim foi uma flagelação muito grande gravar esse negócio. Eu nunca tinha encarado a música sob esse aspecto. Acontece que eu estava querendo provar que os caras não iam conseguir estrepar minha vida. Então, começamos a vender. Duzentos $e$ cinqüenta vendedores de porta em porta aqui no Rio e uns duzentos em São Paulo... Eu achei que ia dar certo, mas não achei que ia ficar muito tempo nesse negócio. Então me chamaram para fazer na Argentina, no Peru, no México, na Venezuela.... ${ }^{18}$

Apesar do sucesso financeiro da empreitada, as lembranças de Midani sobre o período não são muito generosas: "a pior classe, a ralé dos vendedores, é o vendedor de porta em porta. E eu dando curso de vendas, vendendo de porta em porta, coisa que eu nunca tinha feito. Um troço horroroso" 19 . Apesar disso, Midani atribui ao projeto o mérito de ter lhe possibilitado "conseguir gravar bateria como se deveria gravar", com um som mais próximo dos padrões internacionais de captação desse instrumento. ${ }^{20}$

17. Midani afirma em seu depoimento que "gravava todo mundo com outro nome e todo mundo se divertia bastante". De qualquer forma, essa tendência a mimetizar produçōes estrangeiras - que talvez fosse facilitada pelo isolamento do país a que Midani se referiu - iria alcançar seu auge na década seguinte através de diversos cantores e bandas "pseudo-internacionais" como Morris Albert, Light Reflexion, Mark Davis (Fábio Jr.) e Michael Sullivan, entre outros.

18. Depoimento concedido ao autor, op. cit.

19. Midanimidanimidani, op. cit.

20. Depoimento concedido ao autor, op. cit. 
Apesar da obstinação com que Midani busca distanciar o projeto da Imperial Discos de seus valores artísticos e pessoais, fica evidente a atitude pragmática com que ele encarou a nova empreitada, além de sua capacidade, já citada aqui, para detectar e explorar novos nichos de consumo.

Essas qualidades certamente foram determinantes para o seu retorno a uma grande gravadora, que ocorreu em 1964 na forma de um convite para implantar a Capitol no México. A empresa estava sendo criada numa associação entre a Capitol norte-americana e o grupo mexicano de comunicações Televisa. Ele viveria então sua primeira experiência profissional como executivo de uma grande gravadora, responsável pela contratação do elenco e pelo direcionamento artístico da empresa. Para Midani, que ficaria quatro anos no México, o país vivia um momento semelhante ao que ele experimentara anteriormente no Brasil, ou seja, a presença dominante de uma música tradicional diante de uma crescente demanda por uma produção mais alinhada com o mercado jovem. Para atendê-la, Midani buscaria a receita que iria acompanhá-lo por muito tempo: desenvolver um casting de artistas locais, gravando músicas feitas por jovens para um público jovem. E naquele momento, no México, o referencial internacional para a produção dessa música era o rock.

Para Midani, o rock que se fazia no México naquele momento era uma música ingênua e "muito copiada dos brancos norteamericanos". ${ }^{21}$ Sua busca por uma música mais "encorpada", que refletisse melhor a miscigenação étnica e cultural do México, acabou por levá-lo a Tijuana:

Tijuana, naquela época era uma cidade muito especial: era muito pequena, tinha um enorme hipódromo..., alguns cassinos de terceira e uma rua onde praticamente só havia bares e bordéis. Íamos em um bar após o outro e, em um deles, encontramos um grupo de índios magros, altos... que cantavam em inglês e espanhol. Trouxemos o grupo,

21. idem, ibidem

Significação $29 \cdot 126$ 
Los Yaki, para a cidade do México, gravamos e imediatamente foi um enorme sucesso. ${ }^{22}$

O período de Midani no México possibilitou ainda sua maior aproximação com o meio televisivo. $O$ projeto mais importante, nesse sentido, parece ter sido o de produzir a trilha sonora original de uma novela da Rede Televisiva. Tratava-se do folhetim El Derecho de Nacer, radionovela escrita na década de 1940 pelo cubano Félix Caignet $^{23}$. A novela estava recebendo uma nova adaptação televisiva, num projeto que incluía também a produção de um longa-metragem (Tito Davison, 1966) e de uma publicação comemorativa (provavelmente uma foto-novela). Essa experiência, como veremos mais adiante, será bem aproveitada por Midani quando de seu retorno ao Brasil.

\section{Phillips/PolyGram}

Midani volta ao Brasil, em 1968, para assumir a presidência Phillips. ${ }^{24} \mathrm{~A}$ gravadora não se encontrava num bom momento e a incumbência do novo executivo era torná-la lucrativa em três anos ou ela seria fechada. ${ }^{25}$ Ao chegar, Midani se depara com uma empresa que tinha, segundo se lembra, aproximadamente 150 artistas sob contrato. Sua primeira função foi a de reduzir esse cast para algo em torno de 50 nomes. ${ }^{26}$ Midani encarou esse processo de "limpeza"

22. Idem, ibidem. Pode ser relacionada à atuação de Midani a contratação de pelo menos duas outras bandas de rock pela Capitol mexicana: Los Profetas (de Abraham Laboriel) e Los Jets http://rockenmexico2.tripod.com/id22.html.

23. Direito de Nascer foi apresentada também no Brasil e obteve enorme sucesso tanto no rádio quanto na TV (nas décadas de 1950 e 1960, respectivamente).

24. No Brasil, os negócios musicais da Phillips foram iniciados em 1960 através da aquisição da CBD - Cia Brasileira de Discos25. Em 1971 seu nome é modificado para Cia Brasileira de Discos Phonogram e, em 1978, assume a denominação PolyGram (Vicente, 2002: 309). Em 1998 a gravadora foi vendida pela Phillips, tornando-se o cerne da Universal Music

25. Dicionário Cravo Albin da Música Popular Brasileira, op.cit.

26. Idem, ibidem. 
com naturalidade pois, segundo ele, significava liberar a energia necessária para cuidar dos artistas realmente importantes da gravadora: "tinha um sentido evidentemente dramático, mas tinha um sentido regenerador, em poder dar a Elis o que ela merecia, a Caetano, a Gal..."27. E através desse processo de escuta e seleção, Midani se encontra “...com a Tropicália, que estava lá, ainda não desenhada, perdida no meio de 150 artistas" 28 e "era óbvio que iria ser uma coisa importante". ${ }^{29}$

O envolvimento de Midani foi imediato e sua participação no Tropicalismo seria apontada por ele, em 1984, como o momento mais marcante de sua passagem pela indústria. ${ }^{30}$ Quando de sua chegada à Phillips, já eram contratados da gravadora - além dos já citados Elis Regina, Gal Costa e Caetano Veloso - Gilberto Gil, Mutantes, Nara Leão e Jair Rodrigues, entre outros. ${ }^{31}$ Midani começou, então, a contratar artistas vinculados ao Tropicalismo, como Bethânia, e a toda a nova cena da música popular que então se constituía. Durante o período em que esteve à frente da gravadora, foi responsável pelo lançamento de Rita Lee em carreira solo e pela contratação de nomes como Chico Buarque, Erasmo Carlos, Wilson Simonal, Ivan Lins, Jorge Ben, Tim Maia, MPB4 e Raul Seixas, entre outros, além de artistas ligados a segmentos mais populares como Evaldo Braga e Odair José. ${ }^{32}$

Apesar do sucesso que alcançaria na nova função, o fato é que o retorno de Midani ao Brasil não se deu sem sobressaltos. Inicialmente, a própria relação de Midani com Aloysio de Oliveira, seu antigo mentor, passou por momentos difíceis. Aloysio esperava que, agora na presidência de uma grande gravadora, ${ }^{33}$ Midani voltasse

27. Depoimento concedido ao autor, op. cit.

28. Produtor musical sírio-francês André Midani fala de seu papel na MPB, Folha de São Paulo, 28/12/2001

29. Depoimento concedido ao autor, op. cit.

30. Midani, da WEA, aposta na renovação, O Globo, 07/10/1984.

31. Depoimento concedido ao auto, op. cit.

32. Esses artistas eram lançados através do selo Polydor, enquanto os nomes vinculados à MPB eram lançados através do selo Phillips.

33. Que havia, inclusive, adquirido o selo Elenco através de Alain Troussat, antecessor de Midani. 
a se envolver mais intensamente com a Bossa Nova, o que não ocorreu. De qualquer forma, "esses atritos foram desaparecendo quando se verificou que eu continuava trabalhando com João Gilberto, Vinícius de Moraes, Elis Regina e que contratei Menescal como diretor artístico". ${ }^{34}$

Mas, considerando-se o momento político que vivia o Brasil ${ }^{35}$, seria desse campo que viriam, evidentemente, as maiores atribulações do novo diretor. Por um lado, Midani enfrentava resistências porque, como afirmava, "representava um capital estrangeiro e era um estrangeiro". ${ }^{36}$ Nesse campo, o incidente mais marcante foi o texto produzido por Glauber Rocha para o Jornal do Brasil que o tachava como agente da CIA. ${ }^{37}$

Já em relação ao Governo Militar os problemas foram consideravelmente maiores. Embora sem jamais ter assumido publicamente qualquer posicionamento político, Midani parece ter tido um papel ativo no apoio aos artistas da gravadora que foram perseguidos pelo regime, chegando a bancar a gravação de seus discos no exterior quando eles foram exilados, casos de Caetano e Gil (Inglaterra), ou se sentiram forçados a deixar o país, casos de Nara Leão (França) e Chico Buarque (Itália). Midani afirma ter sido obrigado a se submeter a frequientes interrogatórios por suas ações pois "trazia de volta (ao país) um problema que estava lá fora" ${ }^{38}$

34. E-mail enviado ao autor em 16/02/2008.

35. O país vivia sob regime militar implantando a partir de um golpe ocorrido em 31 de março de 1964.

36. Depoimento concedido ao autor, op. cit.

37. Midas Midani, Interview, edição 136, março/1991.

38. Midani por trás das portas à prova de som, $O$ Estado de São Paulo, 27/12/ 1988. Nessa mesma reportagem, Midani afirma ter contratado Wilson Simonal como uma concessão ao governo. Embora reconhecendo-o como "um homem de talento", Midani alega que Simonal gozava da estima dos militares e, com sua presença na gravadora, Midani não iria "parecer tão engajado, só aparecendo na polícia quando dá bode". Ainda segundo ele, a contratação enfrentou forte resistência por parte de outros artistas da gravadora (especialmente Chico Buarque). Em entrevista de 2001, Midani retornaria a esse tema, afirmando que "uma pessoa muito importante do governo militar, que não vou nomear, me pediu para contratar Wilson Simonal. Disse: 'Se você quiser continuar como está, não pode ter só artistas que sejam contra o regime. Tem que ter alguém a favor, tem que contratar o Simonal'. Olhei aquilo com perplexidade, mas tive que contratar", Produtor musical sírio-francês André Midani fala de seu papel na MPB, op. cit. 
Em relação a Caetano e Gil, e falando do tipo de participação que tinha na produção artística de seus contratados, Midani relatava, em 1974, e de maneira ainda forçosamente velada, seu encontro com os dois compositores pouco antes de sua viagem para o exílio: ${ }^{39}$

Os meninos estavam lá completamente abatidos. Estavam na casa deles e não faziam nada. Então, eu me mandei para Salvador e encontrei com eles lá. Fiquei terrivelmente impressionado com aquela depressão deles e nós conversamos muito... Dali saíram os dois discos: o de Caetano, de capa branca, e o do Cristo, do Gil ${ }^{40}$

Em relação a Chico Buarque, Nelson Motta relata que, em 1969, ele se encontrava na Itália em situação econômica difícil quando

...recebeu uma proposta de André Midani para sair da $R G E$ e integrar a "seleção brasileira" da Phillips. E o melhor de tudo: com um adiantamento de 21 mil dólares. $O$ produtor Manuel Barenbein voou para Roma com o contrato e só voltou para o Brasil com uma fita com Chico cantando as músicas do disco... Manuel encomendou os arranjos, gravou os playbacks com a orquestra no Rio e voltou para Roma, onde Chico gravou a voz, no estúdio. ${ }^{41}$

Além de atestar seu relacionamento próximo com contratados da gravadora, a participação de Midani nesses episódios me parece lançar luz sobre seu modo de atuação e sobre a própria situação da indústria no período. O ponto inicial é o de que, segundo

39. Caetano e Gil foram presos no final de 1968, poucos dias após a promulgação do Al-5, Ato Institucional n. 5, que iria reduzir drasticamente as liberdades políticas no país. Eles foram libertados em fevereiro do ano seguinte com a determinação de embarcarem para o exílio, sendo proibidos de realizarem shows no país ou qualquer outra manifestação pública.

40. Midanimidanimidani..., O Pasquim, op. cit. Os discos citados são foram lançados ainda em 1969 e trazem como títulos os nomes de seus autores.

41. Memórias da MPB - Chico no Exílio, Revista Contigo, 26/01/2006. 
suas próprias palavras, ele possuía "uma liberdade total de atuação... sabendo que como executivo de empresa internacional... tinha um respaldo diante do governo". ${ }^{42}$ Entendo que um importante fator a garantir essa "liberdade total" tenha sido a situação amplamente favorável que a indústria fonográfica vivia no país naquele momento. Dentro do processo de desenvolvimento e organização da indústria cultural que então se verificava, a produção de discos no país experimentou um ciclo de crescimento ininterrupto entre os anos de 1966 e 1979. Segundo dados da ABPD, Associação Brasileira dos Produtores de Discos, apenas no período em que Midani se manteve à frente da Phillips, entre 1968 e 1976, o salto da produção nacional de discos foi de 9.8 para 36.9 milhões de unidades. ${ }^{43}$ Além disso, a indústria contava, desde 1967, com uma lei de incentivo que the facultava "abater do montante do Imposto de Circulação de Mercadorias os direitos comprovadamente pagos a autores e artistas domiciliados no país" (Idart, 1980: 118) ${ }^{44}$. Assim, até os gastos gerados pela gravação dos discos dos artistas exilados acabavam cobertos pela isenção de impostos.

Mas mesmo diante desse quadro, acho que seria limitador atribuir a atitude de Midani exclusivamente à sua liberalidade em relação a artistas com quem tinha, seguramente, grandes afinidades artísticas e pessoais. Entendo que a sustentação desse elenco e a gravação desses discos enquadram-se perfeitamente na sua estratégia pessoal de atuação enquanto executivo da indústria, que se baseava na formação de um elenco consolidado junto a seu público numa situação onde, segundo o próprio Midani, o que se promovia era a imagem do artista e não a música que ele gravava. Em palestra proferida na ADVB (Associação dos Dirigentes de Vendas e Marketing do Brasil), em 1975, Midani discute essa questão:

Operar em cima da música ou em cima do artista? Se a companhia de discos escolher a música, ela acaba de

42. Depoimento fornecido ao autor, op. cit.

43. Dados fornecidos pela ABPD e utilizados em minha tese de doutorado (Vicente, 2002: 293).

44. As gravações beneficiadas recebiam o selo "Disco é Cultura". 
entrar em uma mesa de pôquer. Quando ganhar, vai ganhar muito, mas até ganhar... tudo pode acontecer. Se, por outro lado, a indústria opera em cima do artista, ela parte para um artesanato onde a imagem de seu contratado é formada pouco a pouco. O retorno é menos veloz, mas provavelmente será mais duradouro" 45

Assumindo esse segundo modelo, ele "analisava o artista, sacava se ia dar certo ou não e achava totalmente irrelevante analisar a música... existem discos de importantes artistas que eu lancei e nunca ouvi direito"46. Nesse contexto, pode-se compreender a postura política do artista e até sua situação de exilado também como componentes dessa imagem, como elementos para a sua consolidação junto ao público. Não se pretende, aqui, um julgamento dessa estratégia, ou inferir quanto havia de construção nas imagens dos artistas. A questão é apontar para uma situação onde intencionalidade política, experimentação estética e considerações mercadológicas não se colocavam obrigatoriamente como forças antagônicas, estabelecendo uma convivência dentro da indústria do disco da qual Midani foi, sem dúvida, um dos principais artífices. Nesse quadro, as técnicas modernas de marketing não foram de forma alguma desprezadas e, no texto para aDVB, dentro do subtítulo "Publicidade e Promoção", Midani elenca entre as ações desenvolvidas por sua empresa tanto as gravações de seus artistas exilados e presos quanto o uso da "mídia da TV nas telenovelas para reavivar, num determinado momento, a carreira estabelecida de um artista, como por exemplo, Gal Costa e a personagem Gabriela". ${ }^{47}$

Ainda nos termos de sua relação com a TV e as telenovelas, seria importante mencionar a criação, por parte de Midani, Nelson Motta e dos irmãos Marcos e Paulo Sérgio Valle, da produtora

45. MIDANI, A. A Indústria da Loucura Humana, Revista Mercado, n. 35, julho agosto/1975

46. Midani, por trás das portas à prova de som, $O$ Estado de São Paulo, 27/12/ 1988

47. MIDANI, A. A Indústria da Loucura Humana, op. cit. 
Aquarius. A empresa tinha a TV Globo como um de seus principais clientes e produziu para ela os temas de abertura de programas como Globinho, Globo Cor Especial e o tema de final de ano da emissora (Um Novo Tempo, utilizado até hoje). ${ }^{48}$ Os irmãos Valle acabaram também produzindo as trilhas sonoras originais de séries infantis (Vila Sésamo e Sitio do Picapau Amarelo) e de novelas da emissora (como Pigmalião 70, em 1970, e Ossos do Barão, em 1973). Midani lançou a idéia das trilhas originais para novelas a partir de sua experiência no México e o projeto foi rapidamente aceito pela Rede Globo. Porem, apenas uns poucos trabalhos acabaram saindo pela Phillips, já que o próprio sucesso da empreitada fez com que a Globo não renovasse o contrato de parceria e criasse sua própria gravadora, a Som Livre, já em 1971.

Gostaria de retomar a questão da opção de Midani por trabalhar com o artista e não com a música. Sem que evidentemente possamos lhe atribuir esse mérito de forma exclusiva, é forçoso notar que a grande maioria dos artistas aqui citados mantém carreiras ativas até o presente e, de um modo geral, sem a utilização de recursos de revitalização como revivals, tributos, shows acústicos, encontros históricos, etc. Mas apesar desse sucesso, o próprio Midani acabou por reconhecer os limites da estratégia. Considerando a constante busca pelo mercado jovem que mobilizara sua atuação desde o início de sua carreira no país, Midani assinalava, em 1971, o descompasso do mercado brasileiro em relação ao cenário internacional já que, aqui, o consumidor típico de discos teria mais de 30 anos, enquanto no mercado mundial ele estava na faixa de 13 à 25 . Em função disso, ocorria uma divisão etária no mercado, com os consumidores de mais de 25 anos comprando discos de música brasileira - preferencialmente LPs - e os jovens adquirindo música internacional na forma de compactos (Morelli, 1991: 67). Se considerarmos que, na tradição da indústria, as vendas de LPs estão relacionadas a artistas consolidados e as de compactos a músicas de sucesso (Vicente, 2002: 60), é forçoso

48. Nelson Motta promove encontro de Marcos Valle e convidados em SP, Folha de São Paulo, 16/08/2006. 
notar que a estratégia de Midani para a Phillips, embora tenha alcançado grande sucesso comercial e importantes resultados artísticos, acabou não se mostrando eficaz para a conquista de um mercado efetivamente massificado.

Talvez o envelhecimento do cast da Phillips, aumentando ainda mais as dificuldades que Midani encontrava para atingir esse mercado jovem, tenha sido um dos fatores determinantes para a sua saída da empresa, ocorrida em 1976, com o objetivo de dirigir a instalação da WEA (Warner/Elektra/Atlantic) em solo brasileiro. Midani lembra que o convite surgiu de forma fortuita, durante um jantar com Neshui Ertegun, fundador da Atlantic, presidente do grupo e seu amigo de longa data ${ }^{49}$ À época, Midani alegou, como motivação para sua saída da Phillips, a "radical desafinação com os antigos patrões europeus, 'pessoas ótimas, mas rígidas e conservadoras tanto pessoalmente quanto em termos econômicos".. .0

\section{Warner/Elektra/Atlantic}

Mas talvez a desafinação não fosse apenas com os antigos patrões, já que diversas declarações de Midani, no período, acabaram atingindo de alguma maneira seus antigos contratados. A que teve maior reverberação foi, sem dúvida, a de que "o futuro da música brasileira está no rock". Feita no momento de sua saída da Phillips, a afirmação provocou reações irritadas de nomes como Hermínio Belo de Carvalho, Albino Pinheiro, Fagner e Ivan Lins. ${ }^{51}$ Mas não se deve encará-la, necessariamente, como uma visão profética do que seria a explosão do rock brasileiro na década seguinte. Midani foi instado a explicar essa declaração em mais de uma ocasião e, em julho de 1976, afirmava que:

\footnotetext{
49. Eles haviam sido apresentados por Vinícius de Moraes, em Nova York, ainda durante a época da Bossa Nova, conf. depoimento prestado ao autor, op. cit.

50. A Minigravadora Warner e seu Voluntarioso Executivo Midani, Jornal do Brasil, 11/07/1976.

51. Um Chefão das Arábias, Jornal do Brasil, 01/12/1985
} 
Fui mal compreendido quando falei isso. Primeiro, o que chamo de rock brasileiro é Gilberto Gil, Jorge Ben, Erasmo Carlos, Belchior, Caetano, Luis Melodia, Novos Baianos... posso estar esquecendo algum. Não acho, por exemplo, que o rock brasileiro seja a Rita Lee. Porque o que ela faz. é receber uma informação de fora e ajeitar essa informação. Não é criar uma informação de dentro a partir de dados de fora. A segunda coisa que eu quis mostrar às pessoas, é que o rock sofre agora o mesmo preconceito que recebeu a Bossa Nova na época, de que eram vendidos aos americanos, de que eram músicos de jazz. ${ }^{52}$

Mas junto à justificativa, Midani afirmava na mesma reportagem que, em sua nova gravadora, haveriam

...no máximo uns seis contratados nacionais, na faixa dos 30 anos para baixo, compositores que cantem suas próprias músicas... sem preconceito de gêneros ou faixas de público... conscientes de que o disco é um meio moderno e agressivo. Artistas que saibam administrar suas próprias carreiras com noção exata, como João Bosco. Não tenho disposição de querer entender um artesão que recusa e não quer mostrar sua própria estátua. ${ }^{53}$

Não foram, é claro, apenas seis contratados. Essa afirmação "fazia parte de uma estratégia pessoal para transmitir a mensagem a certas pessoas. E a quem interessava chegou". ${ }^{54}$ Assim, embora num primeiro momento a gravadora tenha cuidado de explorar melhor seu catálogo internacional (representado anteriormente no Brasil pela gravadora Continental) e seu primeiro lançamento nacional tenha

52. A Minigravadora Warner e seu Voluntarioso Executivo Midani, op. cit.

53. Idem, ibidem.

54. O Mundo do Disco Segundo Midani, Um Executivo Fora da Rotina, Folha de São Paulo, 30/10/1976. 
sido o álbum "Urubu", de Tom Jobim, gravado nos EUA e negociado previamente com a Warner norte-americana, o elenco nacional foi logo ampliado. E se no ano de 1976 apenas as contratações de Belchior e da estreante Marina foram anunciadas, ${ }^{55} \mathrm{em}$ dezembro de 1977 a gravadora já reunia nomes como Gilberto Gil, Ney Matogrosso, As Frenéticas, Raul Seixas, Cor do Som, Banda Black Rio, Ednardo, Guilherme Arantes, Zezé Motta, Jorge Mello, Carlos Dafé e Candeia, além de João Gilberto, Hermeto Paschoal, Eumir Deodato, Airto Moreira e Flora Purim. ${ }^{56}$ Pouco depois, chegaram Novos Baianos, com os trabalhos solo de Pepeu Gomes e Baby Consuelo, Paulinho da Viola, Tim Maia, Oswaldo Montenegro e Guilherme Arantes, entre outros.

De qualquer forma, acredito que essas e outras declarações de Midani demonstram que sua passagem para a Warner determinou um mudança em sua relação com a mídia, onde a prudência e contenção que haviam caracterizado suas aparições anteriores parecem ter sido deixadas de lado. A impressão que fica é de que Midani buscou a afirmação de uma identidade diferenciada para a empresa tanto através do fortalecimento de sua própria imagem quanto da construção de um discurso próximo daquele que caracterizaria os selos independentes que surgiriam por aqui a partir de 1977. Assim, podem ser pinçados dos títulos e textos de diferentes artigos expressões como "AMinigravadora Warner e seu Voluntarioso Executivo Midani" e "a menor gravadora em ação no país" (ambas no Jornal do Brasil), "uma companhia sem patrão" (Aqui São Paulo), "um executivo fora da rotina" (Folha de São Paulo), etc.

Mas a polêmica mais importante desse seu início com a Warner foi certamente aquela suscitada pelas suas declarações em favor da Black Music, que foram acompanhadas pela contratação de artistas como Carlos Daffé, Banda Black Rio e Tim Maia. Midani

55. Os Filhos da WEA, Aqui São Paulo, 30/09/1976. Porém, o primeiro disco de Marina só seria lançado em 1979.

56. Cantor Nacional Dá Mais Lucro às Multis, Folha de São Paulo, 25/12/1977. Alguns desses últimos nomes já eram, muito provavelmente, contratados da Warner internacional. 
considera, no depoimento que me foi prestado, que sua ligação com a Black Music teve dois momentos distintos. No primeiro deles, ainda na Phillips, ele se limitou à contratação de artistas como Tim Maia, que parece ter sido o primeiro nome do segmento no país, Hildon e Cassiano. Já na Warner, seu contato com uma cena black já mais organizada se deu a partir do convite de um jornalista da Revista Manchete para que ele fosse a um evento em um ginásio esportivo, na Zona Norte do Rio. Impressionado com a força do movimento, Midani começou a divulgá-lo junto a jornalistas do Rio e de São Paulo, além de contratar os artistas já citados. A defesa de Midani ao movimento, diante das críticas acerca de sua evidente influência norteamericana, foram bastante contundentes:

...quando o pobre do negro brasileiro tem a infelicidade de sair de sua favela para fazer outra coisa que não samba, depara-se com uma imprensa branca que diz que ele está perdendo sua negritude, que ele tem de continuar fazendo samba de morro. $\dot{E}$ bonito, mas ao mesmo tempo é o mesmo que dizer: fica na tua favela, vive na tua favela, dana-te na tua favela e morre na tua favela. Recusam a possibilidade dele existir em outra estrutura ou manifestação que não a conhecida ${ }^{57}$

Como conseqüência, Midani acabou alvo de um abaixoassinado que, enviado ao Ministério da Justiça, o apontava como recebedor de fundos do movimento black norte-americano que ele estaria "distribuindo nas favelas para provocar uma guerrilha urbana". ${ }^{58}$ Ainda que o episódio tenha sido particularmente assustador, considerando-se sua condição de estrangeiro que vivia num país sob

57. O mundo do disco segundo um executivo fora da rotina, Folha de São Paulo, $30 / 10 / 1976$.

58. Um chefão das arábias, Jornal do Brasil, 01/12/1985. Segundo a reportagem, Hermínio Bello de Carvalho e Albino Pinheiro, seriam dois dos signatários do abaixo-assinado. 
regime de exceção, ele acabou não tendo maiores repercussões para Midani.

Embora o início de atividades da Warner tenha sido bastante promissor e os álbuns de artistas como Belchior, Gilberto Gil, As Frenéticas, Guilherme Arantes e Oswaldo Montenegro, entre outros, tenham figurado nas paradas do Nopem do final da década de 1970, a empresa acabou engolfada pela grande crise que atingiu a indústria no início da década seguinte, acumulando pesadas perdas. Como conseqüência, a Warner brasileira quase faliu, vendo-se obrigada a abrir mão de sua estrutura de produção e a demitir 400 funcionários, transferindo "a fabricação, distribuição e cobrança para outra gravadora, a Odeon". 59

Midani sentiu fortemente a crise e o fracasso, atribuindo-as à uma mudança no mercado que não conseguira detectar e que seria, para ele, a valorização da música em relação ao artista. Seus depoimentos sobre a época demonstram um forte abatimento e, também, o caminho pelo qual a crise foi superada:

Foi uma catástrofe. Eu era visto como um Midas da música, tudo o que eu via dava certo, e aí chegou o dia em que tudo o que eu via dava errado. Isso aconteceu porque o comportamento do mercado mudou. No período 1968/1977 o que fazia sucesso era o discurso do artista. $O$ importante era o personagem e o que esse personagem falava. Quando chegou em 77, uma das grandes mudanças que começaram a se desenhar é que o personagem ficou relegado a um segundo plano diante da música. Aí eu vi que tinha passado anos sem olhar direito para a música, sem sacar se ela fazia sucesso ou não. Eu fiquei completamente desamparado. De uma posição de muita força eu passei a uma posição de muita fraqueza. Isso coincidiu com a entrada da Ariola no mercado, oferecendo um milhão de dólares naquela época

59. Midani, por trás das portas a prova de som, op. cit. 
para o Chico. Todos os contratos começaram a ser milionários, e eu nunca fui um homem de finanças. Junto a isso ainda houve a recessão de 1980-1982. Uma companhia de discos se consolida muito lentamente, porque ela depende de catálogo e, em três anos, nós ainda não tínhamos catálogo formado. Foi um momento doloroso para mim. Pensei que ia pirar, pensei em cair fora, mas não podia sair assim, por baixo. Comecei então a tentar entender a estratégia de marketing a partir da música, em vez de ser a partir do artista. Passei uns três anos estudando isso e tive a felicidade de ter ao meu lado o Liminha e o Peninha... Aí a companhia foi bem de novo. ${ }^{60}$

Esse novo momento da Warner e da carreira de Midani vincula-se à emergência do rock brasileiro dos anos 80. Em São Paulo, Peninha (Pena Schmidt), que trabalhara anteriormente na Continental, levou até a Warner o projeto de lançamento de compactos de novas bandas como Titãs, Ira!, Ultraje a Rigor e Magazine. Midani apoiou o projeto e os grupos lançaram, posteriormente, álbuns de grande vendagem. Já Liminha, produtor da Warner no Rio, participou das produções dos primeiros trabalhos de alguns nomes mais importantes da cena carioca como Lulu Santos e Kid Abelha.

O protagonismo desses jovens produtores junto ao rock dos anos 80 parece indicar que Midani começava a se afastar do contato direto com os artistas e com o trabalho de produção. Ao ser perguntado, ainda em 1976, se acumularia também na Warner a chefia comercial e a área artística, influindo em carreiras como fizera anteriormente, Midani respondeu:

Devo reconhecer que o tempo vai passando e o meu distanciamento dos meninos que fazem música se torna cada vez maior. E cada vez maior é o perigo deles me

60. Midani Midani, Interview, ed. 136, março/1991. 
considerarem uma imagem paterna, com a qual a comunicação é difícil. $O$ gap da idade para mim já é grande. Já não dá mais. ${ }^{61}$

A partir da segunda metade da década de 80, Midani começa a ser cada vez mais requisitado por Ertegun para projetos internacionais da gravadora, afastando-se aos poucos da cena musical nacional. Seu período à frente da Warner brasileira se encerra definitivamente em 1990, quando ele se muda para Nova York "assumindo a função de Presidente da Warner para a América Latina e, depois, a função de Presidente da Warner Internacional". Em relação a Warner, Midani

...estabeleceu a companhia Latina nos Estados Unidos, consolidou a gravadora no México e na Argentina, instalou a companhia em países como Colômbia, Peru, Venezuela e Chile e fez parte do Conselho de Direção da gravadora na Itália e na Espanha. Tornou-se membro do Conselho Consultivo da gravadora em 2000..., membro do conselho da Federação Internacional dos Produtores de Discos (IFPI) e presidente da IFPI LatinoAmericana. ${ }^{62}$

Após a sua aposentadoria, em 2002, Midani voltou a residir no Brasil. Logo a seguir - e a partir de uma sugestão de seu amigo o jornalista Zuenir Ventura - ele passa a colaborar com a ONG Viva Rio, coordenando o portal Viva Favela, que produz conteúdo para rádios comunitárias. A colaboração se estende até 2005. Entre suas premiações, vale mencionar sua eleição, pela Revista Billboard (1990), como uma das 90 pessoas mais importantes da indústria fonográfica mundial, e sua indicação, em 1999, como Personalidade do Ano pelo Midem Américas.

61. A Minigravadora Warner e seu Voluntarioso Executivo Midani, op. cit.

62. Dicionário Cravo Albin da Música Popular Brasileira, op. cit. 


\section{Conclusões}

Entendo que o papel de Midani à frente da indústria teve várias significações importantes. Em primeiro lugar, considerando sua permanente busca pelo público jovem e sua sintonia com movimentos como a Bossa Nova e o Tropicalismo, ele representou um impulso de modernização num momento em que o crescimento do mercado fonográfico e a expansão de seu público - dentro de um quadro histórico, cultural e político bastante complexo - impunham novas demandas. Assim, num certo sentido, entendo que ele preparou a indústria para o seu encontro com toda uma geração de consumidores e de criadores, tornando-a apta, em relação a esses últimos, a interpretar melhor suas necessidades artísticas e potencialidade comercial.

Em segundo lugar, eu diria que Midani deu uma face à indústria. Sua considerável habilidade política parece ter permitido, como muitos dos textos jornalísticos aqui citados sugerem, um diálogo mais constante com a imprensa e a sociedade, personalizando a atividade do executivo. Sob esse aspecto, talvez seja válido perguntar se a presença de um rosto representativo, com um certa legitimidade política, intelectual e artística, não estaria fazendo falta no conturbado cenário da indústria atual.

Finalmente, devemos destacar o que Midani chama de opção entre promover a música e o artista. Sua forma de atuação, como vimos, baseou-se durante boa parte de sua carreira no investimento na imagem do artista e, como consequiência, na consolidação de carreiras de longa duração. É evidente que Midani não tem a exclusividade nesse campo de atuação e que, como vimos nesse texto, ele também soube lançar mão de estratégias mais imediatistas ao longo de sua carreira (como nas atividades da Imperial Discos, por exemplo). Porém, mesmo considerando que a ênfase de muitos de seus depoimentos na idéia da promoção do artista seja, em alguma medida, uma estratégia de legitimação pessoal, isso não invalida a pertinência do debate: a ênfase na busca por vendas maciças e resultados imediatos, que tende a desconsiderar o processo de formação do artista e sua identificação mais duradoura com o público, 
é o resultado da evolução "natural" da indústria, que teria superado a fase romântica simbolizada por Midani, ou um dos componentes de sua crise atual?

Talvez a sobrevivência de muitas das empresas hoje envolvidas com o mercado fonográfico venha a depender, em alguma medida, da resposta que conseguirão oferecer a essa questão.

\section{Referências Bibliográficas}

IDART, Departamento de Informação e Documentação Artísticas. Disco em São Paulo, Damiano COZZELLA (Org.), São Paulo, Secretaria Municipal de Cultura/ Centro de Pesquisa de Arte Brasileira, 1980

MORELLI, R. C. L., Indústria Fonográfica: Um Estudo Antropológico. Campinas, Ed. Unicamp, Série Teses, 1991

ORTIZ, Renato, A Moderna Tradição Brasileira. São Paulo, Brasiliense, 1988.

VICENTE, Eduardo. Música e Disco no Brasil tese de doutorado não publicada, São Paulo: ECA/USP, 2002.

ZAN, J. R. A Gravadora Elenco e a Bossa Nova. In: Cadernos da Pós-Graduação, Campinas, IA/Unicamp, 1998, v.2, n.1, p. 6470 . 